\title{
Potential intravenous drug incompatibilities in a pediatric unit
}

\author{
Potencial de incompatibilidade de medicamentos intravenosos em uma unidade pediátrica
}

\author{
Karla Dalliane Batista Leal ${ }^{1}$, Ramon Weyler Duarte Leopoldino ${ }^{1}$, Rand Randall Martins ${ }^{1}$, \\ Lourena Mafra Veríssimo ${ }^{1}$
}

\begin{abstract}
Objective: To investigate potential intravenous drug incompatibilities and related risk factors in a pediatric unit. Methods: A cross-sectional analytical study conducted in the pediatric unit of a university hospital in Brazil. Data on prescriptions given to children aged 0-15 years from June to October 2014 were collected. Prescriptions that did not include intravenous drugs and prescriptions with incomplete dosage regimen or written in poor handwriting were excluded. Associations between variables and the risk of potential incompatibility were investigated using the Student's $t$ test and ANOVA; the level of significance was set at $5 \%(p<0.05)$. Relative risks were calculated for each drug involved in potential incompatibility with $95 \%$ confidence interval. Results: A total of 222 children participated in the study; 132 (59.5\%) children were male and $118(53.2 \%)$ were aged between 0 and 2 years. The mean length of stay was $7.7 \pm 2.3$ days. Dipyrone, penicillin G and ceftriaxona were the most commonly prescribed drugs. At least one potential incompatibility was detected in about $85 \%$ of children (1.2 incompatibility/patient ratio). Most incompatibilities detected fell into the non-tested $(93.4 \%)$, precipitation $(5.5 \%)$, turbidity $(0.7 \%)$ or chemical decomposition $(0.4 \%)$ categories. The number of drugs and prescription of diazepam, phenytoin, phenobarbital or metronidazole were risk factors for potential incompatibility. Conclusion: Most pediatric prescriptions involved potential incompatibilities, with higher prevalence of non-tested incompatibilities. The number of drugs and prescription of diazepam, phenobarbital, phenytoin or metronidazole were risk factors for potential incompatibilities.
\end{abstract}

Keywords: Risk factors; Drug therapy; Administration, intravenous; Drug incompatibility; Child

\section{RESUMO}

Objetivo: Avaliar o potencial de incompatibilidade dos medicamentos intravenosos, identificando possíveis fatores de risco em uma unidade pediátrica. Métodos: Trata-se de um estudo observacional analítico do tipo transversal realizado na unidade de pediatria de um hospital de ensino no Brasil. Os dados foram coletados de junho a outubro de 2014 a partir da análise das prescrições de crianças (0 a 15 anos) hospitalizadas. Foram excluídas prescrições sem medicamento intravenoso e com posologia incompletas ou grafia inadequada. $A$ associação entre as variáveis e 0 risco de potenciais incompatibilidades foi determinada pelo teste $t$ de Student e ANOVA, considerando significativo para $p<0,05$. Calculou-se o risco relativo com intervalo de confiança de $95 \%$ de cada medicamento envolvido. Resultados: Duzentos e vinte e duas crianças participaram do estudo, $132(59,5 \%)$ eram do gênero masculino, $118(53,2 \%)$ tinham idade entre 0 a 2 anos e estiveram internados em média $7,7 \pm 2,3$ dias. Os medicamentos mais prescritos foram dipirona, penicilina $\mathrm{G}$ e ceftriaxona. Quase $85 \%$ das crianças apresentaram ao menos uma potencial incompatibilidade, razão de 1,2 incompatibilidades/ paciente. Os tipos de incompatibilidades mais comuns foram: não testada $(93,4 \%)$, precipitação $(5,5 \%)$, turbidez $(0,7 \%)$ e decomposição química $(0,4 \%)$. Os fatores associados a potenciais incompatibilidades foram: número de medicamentos e a prescrição dos medicamentos diazepam, fenitoína, fenobarbital e metronidazol. Conclusão: A maioria das prescrições pediátricas apresentou potenciais incompatibilidades e a incompatibilidade não testada foi o tipo mais comum. 0 número de medicamentos e a prescrição dos medicamentos diazepam, fenobarbital, fenitoína e metronidazol foram fatores de risco para potenciais incompatibilidades.

Descritores: Fatores de risco; Administração intravenosa; Incompatibilidade de medicamentos; Criança

\footnotetext{
1 Universidade Federal do Rio Grande do Norte, Natal, RN, Brazil.

Corresponding author: Lourena Mafra Verissimo - Avenida General Gustavo Cordeiro de Farias - Petrópolis - Zip code: 59012-570 - Natal, RN, Brazil - Phone: (55 84) 3342-9824

E-mail: lourenamafra@yahoo.com.br

Received on: Apr 21, 2016 - Accepted on: May 25, 2016

Conflict of interest: none.

DOI: 10.1590/S1679-45082016A03723
} 


\section{INTRODUCTION}

The clinical condition of hospitalized patients often requires intravenous drug therapy, with potential exposure of patients to several risks and harms. ${ }^{(1,2)}$ The complexity of intravenous drug therapy, drug administration in particular, is the major cause of such problems. Intravenous medication administration is a complex procedure involving several steps, and is therefore prone to error. ${ }^{(3,4)}$

Medication administration errors are common in pediatric medicine and chances of occurrence around $70 \%$ have been reported. ${ }^{(4)}$ Children are more vulnerable to medication administration errors due to off-label drug use, drug dose variation, lack of standardized dosage regimen, dose calculation based on body weight, immaturity of body organs and systems and inability to communicate effectively. ${ }^{(3,5)}$ In a study by Vijayakumar et al.(2) incompatibility issues accounted for most problems related to intravenous drug administration.

Incompatibility refers to unexpected physical and/or chemical interactions between two or more substances in a mixture, with therapeutic safety and efficacy compromise. ${ }^{(6)}$ Incompatibilities may be physical or chemical in nature. Physical incompatibilities result in visible reactions (e.g., precipitation, turbidity, viscosity, color changes and gas production) while chemical incompatibilities are related to drug degradation due to hydrolysis, oxidation or covalent chemical reactions. ${ }^{(6,7)}$ Several factors have been associated with the occurrence of drug incompatibilities, potential of hydrogen $(\mathrm{pH})$ being the most significant. Most drugs are either acids or weak bases; therefore, minimal changes in $\mathrm{pH}$ can translate into incompatibility. ${ }^{(6,8)}$

The incompatibilities may have several consequences, from simple catheter obstruction to patient death. Physical incompatibilities are more likely to occur in clinical practice. ${ }^{(8)}$ Therefore, the multidisciplinary teams must be aware of the problem, bearing in mind the paucity of literature data, lack of knowledge and/ or limited health professional training. Pharmacists receive drug-centered education and are better qualified to advise on drug incompatibility issues. Therefore, these professionals should be part of multidisciplinary healthcare teams. . $^{(2,7,9,10)}$

\section{OBJECTIVE}

To investigate potential intravenous drug incompatibilities and related risk factors in a pediatric unit.

\section{METHODS}

\section{Study design and population}

A cross-sectional analytical study carried out at the pediatric unit of a medium-sized public university hospital, located in Santa Cruz (RN), Brazil. Prescriptions given to children aged 15 years or under, with a minimum of 24-hour inpatient hospital stay and receiving at least one intravenous medication were included in the sample. Prescriptions containing incomplete dosage regimens or written in poor handwriting were excluded. Prescriptions given from June to October 2014 were selected out of convenience.

\section{Data collection}

Data collection was based on prescription analysis. The following variables were considered: gender, age, cause of hospitalization, number of intravenous medications, dosage, length of inpatient hospital stay and presence and type of potential incompatibilities (PI). Medications were grouped according to the World Health Organization (WHO) Anatomical Therapeutic Chemical Classification System (ATC). ${ }^{(11)}$

\section{Potential incompatibilities}

Prescription of one or more intravenous drugs reported to be physically and chemically incompatible were defined as potential incompatibility (PI) in this study. Incompatibilities could not be actually confirmed; therefore the analysis was based on PIs detected in prescriptions. Potential incompatibility classification was based on Micromedex ${ }^{\circledR}$ version 2.0.(12) The following categories were considered: precipitation, turbidity, chemical decomposition, color changes, variable and non-tested. Variable and non-tested categories were included in the PI classification list due to the paucity of studies or conflicting literature data on the drug combinations involved; incompatibility risks in these cases were assumed to be similar to other PIs.

\section{Sample size and statistical analysis}

Sample size calculation was based on the following assumptions: $50 \%$ PI prevalence, $7 \%$ absolute precision plus $10 \%$ to account for potential losses. The level of significance was set at 5\%. Data extracted from 222 prescriptions and arranged in Excel spreadsheets (software Excel ${ }^{\circledast}$ 2010) were analyzed using the Statistical Package for the Social Sciences SPSS ${ }^{\circledR}$ version 18.0. Variables were expressed as mean \pm standard deviation and absolute or relative frequency, as needed. Drug/ 
patient and $\mathrm{PI} /$ patient ratios were calculated by dividing the number of drugs or PIs by the total number of patients, respectively. Associations between variables and the risk of PI were investigated using the Student's $t$ test and ANOVA. Significance was indicated by $\mathrm{p}<0.05$. Whenever PIs were detected, relative risks were calculated for each drug with $95 \%$ confidence interval.

This study was approved by the Research Ethics Committee of the Faculdade de Ciências e Saúde do Trairi, Universidade Federal do Rio Grande, under CAAE number 30951614.1.0000.5568.

\section{RESULTS}

A total of 222 children were included in the study; in that, $132(59.5 \%)$ were male and 118 were aged between 0 and 2 years $(53.2 \%)$. The mean length of stay was $7.7 \pm 2.3$ days. Respiratory diseases were the major cause of hospitalization. Drug/patient ratio corresponded to 2.5, with $135(60.8 \%)$ children receiving up to two drugs. Analgesics (dipyrone), penicillins (penicillin potassium) and other beta-lactams (ceftriaxona) were the most commonly prescribed drugs (Table 1 ).

Table 1. Sample characterization

\begin{tabular}{lc}
\hline Demographic and clinical characteristics & $\mathbf{n}(\%)$ \\
\hline Male gender & $132(59.5)$ \\
Age & $118(53.2)$ \\
0 to 2 years (n, \%) & $104(46.8)$ \\
2.1 to 15 years (n, \%) & \\
Cause of hospitalization & $104(46.8)$ \\
Respiratory diseases & $51(23.0)$ \\
AGECa & $16(7.2)$ \\
Cellulitis & $23(10.4)$ \\
Infections & $28(12.6)$ \\
Other & \\
Drugs & $135(60.8)$ \\
Up to 2 & $87(39.2)$ \\
3 or more & \\
Most commonly prescribed drug classes (ATCMHO) & $176(32.2)$ \\
Analgesics e antipyretics (N02B) & $127(23.2)$ \\
Penicillins (J01C) & $57(10.4)$ \\
Other beta-lactams (J01D) & $49(9.0)$ \\
Systemic corticosteroids (H02A) & $38(6.9)$ \\
Aminoglycosides (J01G) & $28(5.1)$ \\
Antiemetic agents (A04A) & $27(4.9)$ \\
Prokinetic agents (A03F) & $21(3.8)$ \\
Gastro-protective agents (A02B) & $5(0.9)$ \\
Anticonvulsants (N03A) & $4(0.7)$ \\
Anxiolytics (N05B) & World Health \\
Organization. & \\
\hline
\end{tabular}

Potential intravenous drug incompatibilities were detected in $185(83.3 \%)$ children, with $1.2 \mathrm{PI} /$ patient ratio (Table 2). Most incompatibilities detected in prescriptions fell into the non-tested, precipitation, turbidity or chemical decomposition categories $(93.4 \%$, $5.5 \%, 0.7 \%$ and $0.4 \%$, respectively).

Table 2. Potential intravenous drug incompatibilities in pediatric prescriptions and respective types

\begin{tabular}{lr}
\hline & $\mathbf{n}(\%)$ \\
\hline Prescriptions & $185(83.3)$ \\
With PI & $37(16.7)$ \\
Without PI & \\
Type of incompatibility & $15(5.5)$ \\
Precipitation & $2(0.7)$ \\
Turbidity & $1(0.4)$ \\
Decomposition & $255(93.4)$ \\
Non-tested &
\end{tabular}

The number of drugs prescribed was a risk factor for PI (Table 3). Prescription of diazepam, phenytoin, phenobarbital or metronidazole was also associated with increased PI risks (Table 4).

Table 3. Risk factors for potential intravenous drug incompatibility

\begin{tabular}{|c|c|c|c|}
\hline \multirow{2}{*}{ Demographic and clinical characteristics } & \multicolumn{3}{|c|}{ PI } \\
\hline & $\mathbf{M}$ & SD & p value \\
\hline \multicolumn{4}{|l|}{ Gender } \\
\hline Male & 1.4 & 0.7 & $0.583^{b}$ \\
\hline Female & 1.5 & 0.7 & \\
\hline \multicolumn{4}{|l|}{ Age } \\
\hline 0 to 2 years & 1.4 & 0.6 & $0.101^{b}$ \\
\hline 2.1 to 15 years & 1.5 & 0.8 & \\
\hline \multicolumn{4}{|l|}{ Hospital stay } \\
\hline 1 to 8 days & 1.5 & 0.8 & $0.401^{b}$ \\
\hline 9 days or over & 1.4 & 0.7 & \\
\hline \multicolumn{4}{|l|}{ Drugs } \\
\hline Up to 2 & 1.1 & 0.2 & $0.000^{b *}$ \\
\hline 3 or more & 2.1 & 0.7 & \\
\hline \multicolumn{4}{|l|}{ Cause of hospitalization } \\
\hline Respiratory diseases & 0.9 & 0.6 & $0.623^{c}$ \\
\hline $\mathrm{AGEC}^{\mathrm{a}}$ & 1.1 & 0.7 & \\
\hline Cellulitis & 1.2 & 0.4 & \\
\hline Infections & 1.4 & 0.5 & \\
\hline Other & 0.9 & 0.5 & \\
\hline
\end{tabular}


Table 4. Drugs prescribed and risk of potential intravenous drug incompatibility

\begin{tabular}{lrrccc}
\hline Drugs & $\begin{array}{c}\text { Prescriptions } \\
\mathbf{n}(\%)\end{array}$ & $\begin{array}{c}\text { PI } \\
\mathbf{n}(\%)\end{array}$ & $\mathbf{R R}$ & \multicolumn{2}{c}{$\mathbf{9 5 \% \mathbf { c l }}$} \\
\hline Amikacin & $36(13.2)$ & $4(11.1)$ & 1.77 & 0.59 & 5.29 \\
Acyclovir & $1(0.4)$ & $1(2.8)$ & 15.60 & 0.96 & 254.71 \\
Ceftriaxone & $44(16.1)$ & $3(8.3)$ & 1.04 & 0.31 & 3.53 \\
Diazepam & $4(1.5)$ & $8(22.2)$ & $38.79^{*}$ & 11.01 & 136.59 \\
Epinephrine & $2(0.7)$ & $1(2.8)$ & 7.79 & 0.69 & 87.97 \\
Phenytoin & $2(0.7)$ & $3(8.3)$ & $24.77^{*}$ & 4.00 & 153.41 \\
Phenobarbital & $3(1.1)$ & $5(13.9)$ & $29.25^{*}$ & 6.68 & 128.02 \\
Furosemide & $4(1.5)$ & $1(2.8)$ & 3.88 & 0.42 & 35.63 \\
Metoclopramide & $27(9.9)$ & $1(2.8)$ & 0.55 & 0.07 & 4.17 \\
Metronidazole & $4(1.5)$ & $2(5.6)$ & $7.99^{*}$ & 1.41 & 45.15 \\
Ondansetron & $21(7.7)$ & $3(8.3)$ & 2.28 & 0.65 & 8.03 \\
Oxacillin & $22(8.1)$ & $1(2.8)$ & 0.68 & 0.09 & 5.21 \\
Penicillin potassium & $103(37.7)$ & $3(8.3)$ & 0.39 & 0.12 & 1.30 \\
\hline * Significant relative risk & & & & &
\end{tabular}

* Significant relative risk.

PI: potencial incompatibility; RR: relative risk; 95\%Cl: 95\% confidence interval.

\section{DISCUSSION}

This study suggests PIs are common in pediatric medicine and emphasizes the significance of intravenous drug administration safety. Studies investigating incompatibilities in pediatric medicine are scarce; in fact, this is the first Brazilian study on the topic and the first to include incompatibility risk assessment.

Different from trials reporting low numbers of incompatible drug combinations in intensive care settings, ${ }^{(1,9,13)}$ approximately $80 \%$ of children in this study were exposed to PIs. This reflects the effect of preventive measures and strategies in hospitals; however, incompatibilities may still interfere with medication administration. $^{(2)}$

Studies investigating drug compatibility are scarce and tend to be ill-suited for clinical application. ${ }^{(8)}$ High prevalence of non-tested incompatibilities was documented in this study, dipyrone being the major drug involved. Dipyrone is a classical example of nontested PI: the fact that the drug is not on the market in many countries, including the USA, translates into lack of interest in related publications by countries with more robust scientific tradition. ${ }^{(14)}$ The abundance of novel drugs with common off-label pediatric use in the market also contributes to this scenario. To illustrate the point, chemical decomposition of a potassium penicillinphenobarbital combination given at 500,000IU/ml and $65 \mathrm{mg} / \mathrm{ml}$, respectively, has been reported; however, lower concentrations, such as those used in pediatric medicine have not been tested. ${ }^{(12)}$ Lack of data on drug compatibility promotes unsafe drug use in light of the risk of prescribing potentially incompatible drug combinations, not to mention the risk of infections and thrombosis posed by unnecessary venous cannulation. ${ }^{(8)}$
These incompatibilities are strongly associated with the number of drugs prescribed. Similar to drug interactions, associations between the number of drugs prescribed and PI have been reported. ${ }^{(15)}$ The inclusion of drugs like diazepam, phenobarbital, phenytoin and metronidazole in prescriptions is also known to be a risk factor for drug incompatibility. The association of these drugs with PI may reflect reported incompatibilities with dipyrone and penicillin potassium, the most commonly prescribed drugs. ${ }^{(12)}$ Also, phenobarbital and phenytoin are drugs with extreme $\mathrm{pH}$; given $\mathrm{pH}$ is the major factor behind drug incompatibility, such products are more likely to exhibit chemical and physico-chemical interactions. ${ }^{(6,8)}$

Drug administration is a complex procedure and caution is required to avoid medication administration errors and/or incompatibility issues. ${ }^{(4)}$ The following preventive measures are recommended: nursing team guidance and training in drug preparation, administration and potential incompatibilities; implementation of standard operating procedures and distribution of flyers containing data on the most commonly used drugs in clinical practice and instructions for multi-lumen catheter manipulation..$^{(1,13,16,17)}$ Pharmacists are qualified to instruct multidisciplinary teams in drug related problem-solving scenarios; therefore, the involvement of these professionals in drug therapy decisions translates into significant benefits to healthcare services. ${ }^{(2)}$

As previously mentioned, this is the first study on intravenous drug incompatibilities in pediatric medicine, with the added contribution of PI risk factor analysis. The major limitation of this study is the restriction of the analysis to prescriptions, with no data on medication administration procedures as regards PI prevention. Specific focus on prescription and PI and the exclusion of solutions, electrolytes and parenteral nutrition from the analysis are additional limitations; also, cross-sectional experimental design precluded detailed investigation of patient-specific incompatibilities.

Further studies are required for improved understanding of intravenous drug incompatibility issues and ensuing consequences in clinical practice. Future work aimed at incompatibility risk assessment via cross-sectional studies and studies involving other medical centers are among the purposes of this research group. However, development of novel laboratory assays to investigate potential physical and chemical incompatibilities in nontested drug combinations is also crucial.

\section{CONCLUSION}

Potential incompatibilities were detected in most pediatric prescriptions in this study, with higher prevalence of non- 
tested incompatibilities. The number of drugs prescribed and the prescription of diazepam, phenobarbital, phenytoin or metronidazole were associated with higher PI risks.

\section{ACKNOWLEDGEMENT}

The authors thank the management and the team at the pediatric unit where this study was carried out for permission to collect research data and cooperation.

\section{REFERENCES}

1. Bertsche T, Mayer Y, Stahl R, Hoppe-Tichy T, Encke J, Haefeli WE. Prevention of intravenous drug incompatibilities in an intensive care unit. Am J Health Syst Pharm. 2008;65(19):1834-40.

2. Vijayakumar A, Sharon EV, Teena J, Nobil S, Nazeer I. A clinical study on drugrelated problems associated with intravenous drug administration. J Basic Clin Pharm. 2014;5(2):49-53.

3. Doherty C, Mc Donnell C. Tenfold medication errors: 5 years' experience at a university-affiliated pediatric hospital. Pediatrics. 2012;129(5):916-24.

4. McDowell SE, Mt-Isa S, Ashby D, Ferner RE. Where errors occur in the preparation and administration of intravenous medicines: a systematic review and Bayesian analysis. Qual Saf Health Care. 2010;19(4):341-5. Review.

5. Gonzales K. Medication administration errors and the pediatric population: a systematic search of the literature. J Pediatr Nurs. 2010;25(6):555-65. Review.

6. Secoli SR, Pérez-Esquirol E, de las Heras-Matellán MJ, Vendrell-Bosh L, BallarínAlins E. [Incompatibilities in intravenous therapy: what can be done to prevent them?]. Enferm Clin. 2009;19(6):349-53. Spanish.

7. Newton DW. Drug incompatibility chemistry. Am J Health Syst Pharm. 2009; 66(4):348-57. Review. Erratum in: Am J Health Syst Pharm. 2009;66(16):1431.

8. Kanij S, Lam J, Johanson C, Singh A, Goddard R, Fairbairn J, et al. Systematic review of physical and chemical compatibility of commonly used medications administered by continuous infusion in intensive care units. Crit Care Med. 2010;38(9):1890-8. Review.

9. Gikic M, Di Paolo ER, Pannatier A, Cotting J. Evaluation of physicochemical incompatibilities during parenteral drug administration in a paediatric intensive care unit. Pharm World Sci. 2000;22(3):88-91.

10. Nguyen HT, Pham HT, Vo DK, Nguyen TD, van den Heuvel ER, Haaijer-Ruskamp $\mathrm{FM}$, et al. The effect of a clinical pharmacist-led training programme on intravenous medication errors: a controlled before and after study. BMJ Qual Saf. 2014;23(4):319-24.

11. World Health Organization (WHO). WHO Collaborating Centre on Drug Statistics Methodology. ACT/DDD Index 2016 [Internet]. Oslo, Noruega: WHO; 2015. [cited 2016 Apr 15]. Available from: http://www.whocc.no/atc ddd index/

12. Micromedex Solutions ${ }^{\circledR}$ Healthcare Series of Database Versão 2.0 [Internet]. Greenwood Village (CO): Thomson Micromedex; 2016. [cited 2016 Apr 15]. Available from: http://www.micromedexsolutions.com

13. Machotka O, Manak J, Kubena A, Vlcek J. Incidence of intravenous drug incompatibilities in intensive care units. Biomed Pap Med Fac Univ Palacky Olomouc Czech Repub. 2015;159(4):652-6.

14. Food and Drug Administration (FDA). List of drug products that have been withdrawn or removed from the market for reasons of safety or effectiveness [Internet]. Federal Register. 1998;63(195):54082-9 [cited 2016 May 25]. Available from: https://www.gpo.gov/fdsys/pkg/FR-1998-10-08/pdf/98-26923.pdf

15. Fernández de Palencia Espinosa MA, Díaz Carrasco MS, Fuster Soler JL, Ruíz Merino G, De la Rubia Nieto MA, Espuny Miró A. Pharmacoepidemiological study of drug-drug interactions in onco-hematological pediatric patients. Int J Clin Pharm. 2014;36(6):1160-9.

16. Manrique-Rodríguez S, Sánchez-Galindo A, Mora-García T, FernandezLlamazares CM, Echarri-Martínez L, López-Herce J, et al. Development of a compatibility chart for intravenous $Y$-site drug administration in a pediatric intensive care unit. J Infus Nurs. 2012;35(2):109-14.

17. Perez $M$, Décaudin B, Foinard A, Barthélémy $C$, Debaene B, Lebuffe $G$, et al. Compatibility of medications during multi-infusion therapy: a controlled in vitro study on a multilumen infusion device. Anaesth Crit Care Pain Med. 2015; 34(2):83-8. 